\title{
MINPL optimization of timber trusses considering joint flexibility
}

\author{
S. Šilih, S. Kravanja, P. Dobrila \& M. Premrov \\ University of Maribor, Faculty of Civil Engineering, Slovenia
}

\begin{abstract}
The paper presents the shape and discrete sizing optimization of timber trusses with the consideration of joint flexibility. The optimization was performed by the Mixed-Integer Nonlinear Programming (MINLP) approach. In the optimization model an economic objective function for minimizing the structure's selfmanufacturing costs was defined. The design conditions in accordance with Eurocode 5 were considered as optimization constraints. The internal forces and deflections were calculated by finite element equations. The structural stifness matrix was composed by considering fictiously decreased cross-sectional areas of all the flexibly connected elements. The cross-section dimensions and the number of fasteners were defined as discrete sizing variables, while the joint coordinates were considered as shape variables. The applicability of the proposed approach is demonstrated through a numerical example, presented at the end of the paper.

Keywords: timber, trusses, joint flexibility, shape optimization, discrete sizing optimization, mixed-integer nonlinear programming.
\end{abstract}

\section{Introduction}

Timber construction is an important part of the infrastructure in a number of areas around the world. Wood has proved to be quite a resilient material, showing relatively high ductility and low density. In addition, the flexibility of mechanical fasteners provides a high damping capacity between the connected timber elements. Well-built timber structures maintain a good performance particularly under the influence of wind and especially earthquake forces.

In the last decades, the application of timber trusses has frequently been noticed in all aspects of building construction. Timber trusses have become 
known for their pleasing architectural appearance, lightweight design and easy fabrication. The use of timber trusses to bridge over large open areas with a few or no intermediate supports is still on the increase. These trusses are essentially lighter than the analogous beam solutions. Many magnificent space and plane timber trusses have been constructed all over the world, covering public halls, stadiums, exhibition centres and many other buildings. In this field, metal-plateconnected timber trusses have been found to be favourable structures for roof framings for spans greater than 20 meters.

In order to design a satisfactory and optimal timber truss structure with the given load, span and boundary conditions, some main design parameters need to be considered, on which timber truss behaviour basically depends:

- type of truss configuration,

- span/depth ratio,

- number and type of intermediate members (diagonals and verticals),

- type of joint connections.

When a high number of truss design parameters, designer decisions and factors are involved in the analysis, the designing of timber trusses can become a difficult and expensive process. This has forced designers to find simpler and cheaper alternative design methods, adequate at least for the preliminary design state. Several approximate methods have been developed in the recent past with different accuracies of suitability and simplification according to real truss conditions, see [1]. Approximate designing methods which additionally consider the flexibility of the joints in timber trusses with respect to different diagonal members can for example be found in [2-5].

The idea of the present study was to together simultaneously consider all the mentioned design parameters and factors in a single mathematical truss model, where structural optimization is performed rather than classical analysis.

For more than four decades, trusses have not only been successfully optimized but also very frequently used to present, test and improve various optimization techniques. Numerous research papers on this topic have been published since the early 1960s, e.g. [6]. While many papers discuss the topology, shape and discrete sizing optimization particularly of steel trusses, e.g. [7-10]; also the optimization of composite trusses, [11]; timber trusses have been quite neglected.

The present paper represents a continuation of the research work introduced in [12]. In the preliminary work, the optimization of timber trusses with special attention to joint flexibility was carried out by using the Non-linear Programming (NLP) approach. Sizing optimization of pitched trusses with a fixed slope of the top chord was performed for different S/D ratios and different numbers of intermediate members. The design constraints were defined in accordance with the European standard for the design of timber structures, Eurocode 5 [13]. The corresponding ultimate limit state (ULS) and serviceability limit state (SLS) conditions were considered. An economic objective function representing the manufacturing costs of the structure was introduced. It has been proven that flexible joint connections exercise a significant influence on the final structural design. A comparative numerical study demonstrated that the 
manufacturing costs can increase by over $10 \%$ and the timber mass by over 15 $\%$ if the flexibility of the joints is additionally considered in the design process. The influence becomes greater when the number of flexibly connected members increases. Trusses with a lower number of diagonals and verticals have thus proven to be more convenient. Besides, lower $\mathrm{S} / \mathrm{D}$ ratios have also proven to be preferable. At a larger depth of the truss, the stress-controlled (ULS) conditions become decisive instead of the deflection-controlled (SLS) ones.

The present study additionally includes the shape optimization of timber trusses. In this way the $\mathrm{S} / \mathrm{D}$ ratio (the depth of the truss girders) as well as the slope of the top chord are optimized simultaneously with the CS dimensions and joint connections (required number of embedded fasteners). In addition, discrete sizing optimization is also performed. In the previous research the application of the continuous NLP optimization approach was demonstrated. Using NLP, the sizing variables (CS dimensions, number of fasteners in each joint) take some real value between the defined lower and upper bound. In order to obtain a structure of practical applicability, these variables have to be rounded to the nearest upper discrete value (e.g. $1 \mathrm{~cm}$ for CS dimensions; 1 fastener). Subsequently, the structure has to be reanalysed. Using discrete sizing optimization, on the other hand, the discrete/standard values for sizing variables are calculated simultaneously during the optimization process. Alongside continuous variables (shape varibles, stresses, deflections, etc.), discrete variables are also included. The problem thus corresponds to a mixed discrete/continous type of optimization problems, which can be solved with the use of the Mixed-Integer Non-Linear Programming (MINLP) optimization approach. For the solution of the defined problem, the Modified Outer Approximation/ Equality Relaxation (OA/ER) algorithm [14] was applied.

\section{Timber truss design criteria}

The design constraints for the timber trusses were determined in accordance with Eurocode 5 [13] in order to satisfy the requirements of both the ultimate (ULS) and the serviceability limit state (SLS). Considerng the ULS, the truss members were checked for the tensional as well as the compressive/buckling resistance. The reqired number of fasteners were also calculated for each joint. At the SLS the vertical deflections of the truss girders were checked.

Since the bracing members (diagonals and verticals) are flexibly connected, their stiffness decreases. In finite element analysis we consider the joint flexibility in such a way that cross-sectional areas $A_{m}$ of all bracing members are replaced by a fictiously decreased cross-section area $A_{m}{ }^{*}[4]$ :

$$
A_{m}^{*}=\frac{A_{m}}{1+\frac{E_{m, \text { mean }} \cdot A_{m}}{L_{m}} \cdot\left(\frac{1}{K_{s e r} \cdot k_{m, 1}}+\frac{1}{K_{s e r} \cdot k_{m, 2}}\right)}
$$

where $k_{m, 1}$ and $k_{m, 2}$ represent the numbers of fasteners at both ends of the considered $m$-th bracing element and $K_{\text {ser }}$ denotes the fasteners' slip modulus, 
taken for different types of fasteners from Table 7.1 of Eurocode 5. $E_{m \text {,mean }}$ stands for the mean value of the modulus of elasticity.

\section{MINLP optimization of timber trusses}

The general non-linerar continuous/discrete optimization problem (MINLP-G) can be formulated as follows:

$$
\begin{gathered}
\min z=\boldsymbol{c}^{\mathrm{T}} \boldsymbol{y}+f(\boldsymbol{x}) \\
\text { s.t. } \boldsymbol{h}(\boldsymbol{x})=\boldsymbol{0} \\
\boldsymbol{g}(\boldsymbol{x}) \leq \boldsymbol{0} \\
\boldsymbol{B} \boldsymbol{y}+\boldsymbol{C} \boldsymbol{x} \leq \boldsymbol{b} \\
\boldsymbol{x} \in X=\left\{\boldsymbol{x} \in R^{n}: \boldsymbol{x}^{\mathrm{LO}} \leq \boldsymbol{x} \leq \boldsymbol{x}^{\mathrm{UP}}\right\} \\
\boldsymbol{y} \in Y=\{0,1\}^{m}
\end{gathered}
$$

(MINLP-G)

where $\boldsymbol{x}$ is a vector of continuoius variables specified in the compact set $X$ and $\boldsymbol{y}$ is a vector of binary $0-1$ variables. Functions $f(\boldsymbol{x}), \boldsymbol{h}(\boldsymbol{x})$ and $\boldsymbol{g}(\boldsymbol{x})$ are continuous and differentiable non-linear functions involved in the objective function $z$, equality and inequality constraints, respectively. Finally, $\boldsymbol{B} \boldsymbol{y}+\boldsymbol{C} \boldsymbol{x} \leq \boldsymbol{b}$ represents a subset of mixed linear equality/inequality constraints.

In the context of the considered trimber truss optimization, continuous variables define continuous structure parameters (nodal coordinates, internal forces, deflections, etc.) while binary variables are linked to the discrete/standard CS dimensions. Equality and inequality constraints and the bounds on continuous variables represent a rigorous system of functions taken from structural analysis. Logical constraints that must be fulfilled for discrete decisions and structure configurations are given by $\boldsymbol{B} \boldsymbol{y}+\boldsymbol{C} \boldsymbol{x} \leq \boldsymbol{b}$. In this paper, the economic objective function $z$ is proposed to minimize the structure's selfmanufacturing costs. It involves fixed costs charges in the term $\boldsymbol{c}^{\mathrm{T}} \boldsymbol{y}$ for manufacturing, while the dimension dependant costs are included in the function $f(x)$.

The MINLP optimization model for the optimization of timber trusses was developed according to the above model formulation. GAMS (General Algebraic Modeling System), [15], was used as the interface for mathematical modeling and data inputs/outputs.



Figure 1: $\quad$ Plane timber truss. 
A general timber truss layout with its characteristic elements (upper and lower chord, verticals, diagonals) is presented in Figure 1, where $x_{i}$ represents the local longitudinal axis of element $i$, while $y_{i}$ and $z_{i}$ represent the principal axes of the cross-section of the element $i$; the axes $\mathrm{X}$ and $\mathrm{Y}$ form the global coordinate system of the structure. $A_{i}$ and $l_{i}$ stand for the cross-section area and the length of member $i$, rescpectively. The cross-sections are considered to be rectangular, where $b_{i}$ and $h_{i}$ represent the width and the height of the cross-section of the truss member $i$.

An economic objective function is defined in the model to minimize the structure's self-manufacturing costs, subjected to design, stress and stability constraints, known from structural analysis. Internal forces are proposed to be determined by the finite element equations, while the dimensioning is performed in accordance with Eurocode 5. The objective function is thus defined:

$$
\min \quad \operatorname{cost}=c_{t} \cdot \sum_{i=1}^{I} b_{i} h_{i} l_{i}+\left(c_{f m}+c_{f l}\right) \cdot 2 \cdot \sum_{m=1}^{M} k_{m}+\left(c_{f m}+c_{f l}\right) \cdot \sum_{j=1}^{J} k_{j}
$$

where cost represents the self-manufacturing (material and labour) costs of the structure; $c_{t}$ denotes the price of the manufactured and embedded timber material per $\mathrm{m}^{3}$; the sum of the products between widths $b_{i}$, heights $h_{i}$ and lengths $l_{i}$ of $i$, $i \in I$, timber members represents the volume of the truss in $\mathrm{m}^{3}$ (see Figure 1 ); $c_{f m}$ is the material cost of one fastener together with the adjoining steel plates, while $c_{f l}$ denotes the manual labour costs for handling, assembling, drilling and bolting, defined per one fastener. Considering that the required number of fasteners is equal for both ends of each intermediate member, the total number of fasteners in the $m$-th member is $2 k_{m}$, where $k_{m}=k_{m, 1}=k_{m, 2}$. The last term of the objective function represents the sum of all fasteners required in joints of the chord members. Variable $k_{j}$ stands for the number of fasteners of the $j$-th joint, $j \in J$. It is evaluated considering the resultant force on account of the axial forces of all intermediate elements connected to joint $j$. Since the dimensions of steel plates depend directly on the number of calculated fasteners, the costs of steel plates are included in the values $c_{f m}$ and $c_{f l}$.

The input data of the optimization model is the initial truss geometry (coordinates of joints), the supporting and loading conditions, the diameter of the considered fasteners, the thickness of the metal plates, as well as the material characteristics of all the used components (timber, fasteners, plates).

The cross-section dimensions $b_{i}$ and $h_{i}$ of $i, i \in I$, truss timber members and the number of fasteners $k_{m}$ and $k_{j}$ are defined as discrete optimization variables, while the structural height and the slope of the top chord are defined as continuous optimization variables.

The finite element equations for the calculation of internal forces and deflections of the structure are defined as equality constraints. The stiffness matrix of the structure is composed by considering the fictiously decreased cross-section areas of all the intermediate timber elements (diagonals and verticals) in accordance with Eq. (1). The ULS and SLS design conditions, described in Section 2 are defined as inequality constraints. 


\section{Numerical example}

As a numerical example, a timber truss girder of $22.5 \mathrm{~m}$ span is presented. The layout of the structure is shown in Figure 2. The truss elements are composed from a glued laminatetd timber GL32h according to the EN 1194 [16] classification. M14 dowels made of steel S 235 are used as fasteners. Steel plates of $8 \mathrm{~mm}$ thickness made of steel S 235 are additionaly placed as the central members of a double shear connection.

The truss is subjected to a permanent load of $2 \mathrm{kN} / \mathrm{m}$ and a variable load of 5 $\mathrm{kN} / \mathrm{m}$ (snow load). The self-weight of the truss memebers was automatically determined through the optimization process with respect to the actual calculated cross-sectional dimensions. The uniform loads are, in the calculation, approximated as nodal forces (see Figure 2).

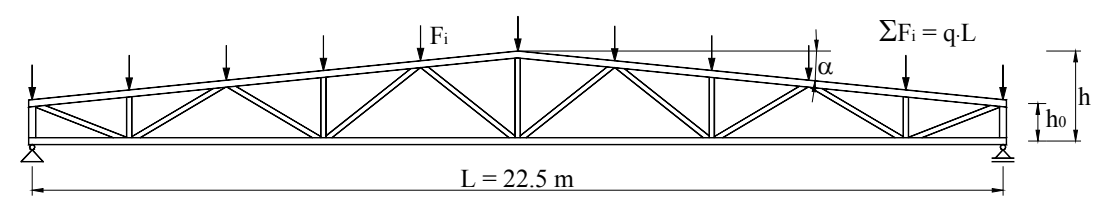

Figure 2: $\quad$ Layout of the timber truss.

Table 1: $\quad$ The comparison of optimal results.

\begin{tabular}{|c|c|c|c|}
\hline & & $\begin{array}{c}\text { MINLP } \\
\text { Present result }\end{array}$ & $\begin{array}{c}\text { NLP } \\
\text { Reference [12] }\end{array}$ \\
\hline Total costs & [EUR] & 1683.03 & 1865.35 \\
\hline Timber mass & {$[\mathrm{kg}]$} & 700.29 & 766.86 \\
\hline \multicolumn{4}{|c|}{ Chord dimensions $\mathrm{b} / \mathrm{h} \quad[\mathrm{cm}]$} \\
\hline & lower chord & $12 / 13$ & $12 / 13$ \\
\hline & upper chord & $16 / 13$ & $17 / 13$ \\
\hline Total number & f dowels & 149 & 155 \\
\hline \multicolumn{4}{|c|}{ Truss geometry } \\
\hline & $\mathrm{h}_{0}[\mathrm{~cm}]$ & 120.81 & 187.50 (fixed) \\
\hline & $\mathrm{h} \quad[\mathrm{cm}]$ & 319.55 & 300.00 (fixed) \\
\hline & $\left.\alpha \quad{ }^{\circ}\right]$ & 10.02 & 5.71 (fixed) \\
\hline $\begin{array}{l}\text { Max. deflecti } \\
\text { considering jc }\end{array}$ & $\begin{array}{l}\text { n without } \\
\text { nt flexibility }[\mathrm{mm}]\end{array}$ & 35.00 & 32.80 \\
\hline $\begin{array}{l}\text { Max. deflecti } \\
\text { joint flexibilit }\end{array}$ & $\begin{array}{l}\text { n by considering } \\
{[\mathrm{mm}]}\end{array}$ & 48.50 & 46.07 \\
\hline
\end{tabular}


The economic parameters considered for the objective function (2) were costs $c_{t}=900 \mathrm{EUR} / \mathrm{m}^{3}$ for the GL32h timber, while $c_{f l}=1.5 \mathrm{EUR}$ and $c_{f m}=1.0 \mathrm{EUR}$ for one M14 S 235 dowel (including the corresponding parts of the steel plates). The vectors of discrete values for both CS dimensions, $b_{i}$ and $h_{i}$ were defined as $\boldsymbol{q}_{l}^{b} \equiv \boldsymbol{q}_{l}^{h}=\{8,9,10,11,12,13,14,15,16,17,18,19,20\}[\mathrm{cm}]$. The bounds on shape variables (see Figure 2) were taken as: $h_{0}{ }^{l o} / h_{0}^{u p}=87.5 / 300 \mathrm{~cm}, h^{l o} / h^{u p}=$ $187.5 / 487.5 \mathrm{~cm}$ and $\alpha^{o} / \alpha^{u p}=0^{\circ} / 15^{\circ}$. This way, a flat truss $\left(\alpha=0^{\circ}\right)$ is also considered a possible solution.

The optimization was carried out by a user-friendly version of the MINLP computer package MIPSYN, the successor of PROSYN [14] and TOP [17]. MIPSYN represents the implementation of the Modified OA/ER algorithm, wher within the optimization process, the GAMS/CONOPT2 (Generalized reduced gradient method) [18] was used to solve NLP subproblems and the GAMS/Cplex 7.0 (Branch and Bound) [19] was used to solve MILP master problems.

The calculated optimal values of optimization variables are presented in Table 1. The obtained result is compared to the results presented in [12], where a continuous NLP optimization with the successive rounding of variables and reanalysis was performed.

From the results presented in Table 1 it is evident, that a considerable reduction in the total costs and timber mass was obtained by the inclusion of shape and discrete sizing variables. Both quantities were reduced by something less than 10 percent. Although the MINLP solution results in slightly larger deflections, the calculated deflections are still perceptible smaller than the allowed ones $(75 \mathrm{~mm})$ and the ULS (stress/buckling) design conditions remain decesive.

\section{Conclusions}

The paper presents the shape and discrete sizing optimization of metal-plate connected plane timber trusses by considering the flexibility of the joints. The optimization was performed by the Mixed-Integer Non-Linear Programming (MINLP) approach. The main objective was to obtain a truss structure, which would be optimal with respect to different design parameters such as span to depth ratio, slope of top chord, etc. in a simultaneous optimization process. The discrete sizing optimization enables the discrete/standard values of sizing variables (CS dimensions, number of fasteners in each connection) to be calculated directly in the optimization process and that no re-analysis is required.

The presented numerical example and the subsequent comparison of results obtained using different optimization techniwues and different levels of optimization exposed the benefits of the proposed MINLP optimization approach.

\section{References}

[1] Hoyle RJ, Woeste FE. Wood Technology in the Design of Structures, Ames, Iowa: Iowa State University Press, 1989. 
[2] El-Sheikh A. Approximate Analysis of Space Trusses. International Journal of Space Trusses 1996; 11: 321-30.

[3] Stalnaker J, Harris E. Structural Design in Wood, NY: Van Nostrand Reinchold, 1989.

[4] Steck G.. Fachwerbinde aus Brettschictholz un Vollholz, Holzbauwerke: Bauteile Step 2, Konstruktionen, Details nach Eurocode 5, Düsseldorf: Fachverlag Holz, 1995.

[5] Brüninghoff $\mathrm{H}$ et. al. Eine Ausführliche Erläuterung zu DIN 1052, Teil 1 bis Teil 3, Beuth -Kommentare, Berlin: Beuth Bauverlag, 1988.

[6] Schmidt LA Structural Design by Systematic Synthesis. Proceedings of $2^{\text {nd }}$ Conference on Electronic computations; NY: ASCE, 1960, 105-22.

[7] Lipson SL, Agrawai KM. Weight Optimization of Plane Trusses. ASCE Journal of the Structural Division 1974; 100: 865-79.

[8] Prager W. Optimization of Structural Design. Journal of Optimization Theory and Applications 1970; 6: 1-21.

[9] Šilih S, Kravanja S, Bedenik BS. Shape optimization of plane trusses. In: Hendriks, MAN, Rots JG editors, Finite Elements in Civil Engineering Applications, Proceedings of the Third DIANA World Conference, Tokyo, 2002, 369-73.

[10] Kaveh A, Kalatjari V. Topology optimization of trusses using genetic algorithm, force method and graph theory. International Journal for Numerical Methods in Engineering 2003; 58: 771-91.

[11] Kravanja S, Šilih S. Optimization based comparison between composite I beams and composite trusses. Journal of Constructional Steel Research 2003; 59: 609-25.

[12] Šilih S, Premrov M, Kravanja S. Optimum design of plane timber trusses considering joint flexibility. Engineering structures 2005; 27: 145-154.

[13] CEN/TC 250/SC5 N173, Eurocode 5: Design of Timber Structures, Part 11 General rules and rules for buildings, Final draft prEN 1995-1-1, Brussels, European Comitee for Standardization, 2002.

[14] Kravanja Z, Grossmann IE. New developments and capabilities in PROSYN - an automated topology and parameter synthesizer. Computers in Chemical Engineering 1994; 18: 1097-114.

[15] Brooke A, Kendrick D, Meeraus A. GAMS - A User's Guide, Redwood City, CA: Scientific Press, 1988.

[16] EN 1194, Timber structures - Glued laminated timber - Strength classes and detemination of characteristic values, Brussels, European Comitee for Standardization, 1999.

[17] Kravanja S, Kravanja Z, Bedenik BS. The MINLP approach to structural synthesis, Part I: A general view on simultaneous topology and parameter optimization. International Journal for Numerical Methods in Engineering 1998; 43: 263-92.

[18] Drud AS. CONOPT - A Large-Scale GRG Code. ORSA Journal on Computing 1994; 6:207-16.

[19] CPLEX user notes, ILOG inc. 